\title{
PENGEMBANGAN MODEL RUANG KELAS BERBASIS TEMATIK DI SEKOLAH DASAR
}

\author{
Ludfi Arya Wardana ${ }^{1}$ \\ Afib Rulyansah ${ }^{2}$ \\ 1,2Universitas Panca Marga Probolinggo, ludfiaryawardana@upm.ac.id
}

\begin{abstract}
The purpose of this study was to produce a thematic-based classroom model in grade $\mathrm{V}$ at Tisnonegaran 1 Elementary School in Probolinggo City. This research and development method used Borg \& Gall, which had adapted and consisted of (1) confidential information, (2) planning, (3) product development, (4) expert validation, (5) field trials, (6) final products. The results of the study showed that the learning technology expert validation reached $97.2 \%$, the linguist's validation result showed $90.6 \%$, and the result of the field trial that used readability test met $92.8 \%$. The product of the thematic-based classroom model in primary school has a strong level of validation and a high level of openness. Suggestions for further development can use different classes and levels.
\end{abstract}

Keywords: classroom model, thematic-based learning, elementary school, learning environment

\begin{abstract}
Abstrak: Tujuan dari penelitian ini adalah untuk menghasilkan model ruang kelas berbasis tematik di sekolah dasar di kelas V di Sekolah Dasar Tisnonegaran 1 di Kota Probolinggo. Metode penelitian dan pengembangan ini menggunakan Borg \& Gall yang diadaptasi menjadi 6 tahap yaitu: (1) informasi rahasia, (2) perencanaan, (3) pengembangan produk, (4) validasi ahli, (5) uji coba lapangan, (6) produk akhir. Hasil penelitian menunjukkan validasi ahli teknologi pembelajaran $97,2 \%$, validasi ahli bahasa $90,6 \%$ dan uji coba lapangan dari tes keterbacaan $92,8 \%$. Hal ini menunjukkan bahwa produk pengembangan model ruang kelas tematik di sekolah dasar memiliki tingkat validasi yang kuat dan tingkat keterbukaan yang tinggi. Saran untuk pengembangan lebih lanjut dapat menggunakan kelas dan level yang berbeda.
\end{abstract}

Kata kunci: model ruang kelas, pembelajaran tematik, sekolah dasar, lingkungan belajar

Keberhasilan suatu pembelajaran dapat dipengaruhi oleh banyak hal, salah satunya adalah kondisi lingkungan. Kondisi lingkungan yang baik dapat berdampak positif terhadap proses pembelajaran, dengan lingkungan yang menarik akan tercipta suasana belajar yang menggairahkan. Lingkungan yang ditata secara sistematis, teratur, dan terencana memiliki implikasi pada banyak hal, diantaranya memunculkan respon baik siswa dan menjadi sarana untuk membangun dan mempertahankan sikap positif (Kartika, Natajaya, \& Rihendra, 2013; Maryana \& Rachmawati, 2013).

Lingkungan fisik kelas juga memiliki pengaruh terhadap proses perkembangan siswa sekolah dasar. Unsur lingkungan sebagai objek yang ada disekitar siswa termasuk ukuran kelas, 
rancangan perabotan, temperatur, kelembaban, warna, suara, pergerakan, udara, aroma, dan pencahayaan memiliki pengaruh terhadap perkembangan kognitif siswa (Rands \& Gansemer-Topf, 2017; Weinstein, 1981). Hal ini juga didukung oleh pendapat Wetherill (2002) yang mengungkapkan bahwa perlakuan kelas akan memberikan dampak pada siswa (Wetherill, 2002). Lebih lanjut mendukung proses dan mewujudkan hasil belajar yang maksimal guru perlu memperhatikan pengelolaan lingkungan fisik kelas dengan baik (Cheryan, Ziegler, Plaut, \& Meltzoff, 2014).

Salah satu potret penataan lingkungan fisik kelas dapat diamati di SDN Tisnonegaran I Kota Probolinggo. Hasil observasi menunjukkan bahwa pengaturan tempat duduk siswa terlihat kurang praktis, terbukti tampak meja kursi ditata secara berderet memanjang, berjajar dengan ruang di tengah yang kurang lebar, sehingga saat pembelajaran berlanggsung terlihat guru kesulitan mendekat untuk mengontrol hasil karya siswa yang duduk berada di tengah (9/9/16). Selain itu, siswa terlihat kesulitan untuk keluar atau masuk tempat duduk mereka. Saat pembentukan kelompok siswa terlihat kesulitan, mereka harus menggeser, mengangkat dan memindah meja kursi terlalu jauh melewati teman-temannya untuk bergabung dengan kelompok. Pada saat itu terlihat siswa perempuan tampak kesulitan saat mengangkat meja sendirian, keadaan tersebut mengakibatkan kegaduhan di dalam kelas dan mengganggu siswa lainnya. Saat pembelajaran berlangsung peneliti juga melihat beberapa siswa tampak kesulitan mengakses sumber belajar dikarenakan letaknya berada di atas almari yang cukup tinggi sehingga siswa harus mengambilnya dengan naik kursi.

Pada hari yang sama, dilakukan wawancara untuk mengonfirmasi dan menggali informasi mengenai pandangan guru terhadap penataan fisik kelas (9/9/16). Hasil wawancara awal dengan guru Kelas V SDN Tisnonegaran I Kota Probolinggo menunjukkan bahwa guru belum melakukan ruang kelas karena belum paham dan tidak ada petunjuk tentang desain penataan kelas berbasis tematik. Hasil wawancara juga terlihat bahwa pengetahuan guru tentang ruang kelas masih terbatas, selain itu salah satu faktor kendala guru dalam melakukan pengembangan ruang kelas yaitu belum adanya buku panduan khusus tentang ruang kelas. Peneliti selanjutnya melakukan wawancara dengan siswa kelas $\mathrm{V}$ mengenai pemaknaan mereka terhadap lingkungan kelas. Terlihat siswa cenderung bosen dengan penataan kelas yang monoton, tidak ada poster atau gambar di dinding, cenderung rumit dalam memindahkan dan mengembalikan posisi bangku ketika berkelompok.

Berdasarkan pengumpulan informasi di atas, maka dapat disimpulkan bahwa permasalahan yang terjadi yaitu: (1) lingkungan fisik kelas belum dikelola dengan maksimal, sehingga mengakibatkan kendala pada saat pembelajaran, (2) adanya kejenuhan siswa, sehingga muncul keinginan untuk ruang kelas yang baru, dan (3) guru mengalami kendala dalam melakukan ruang kelas dikarenakan belum adanya buku panduan khusus untuk menruang kelas. Kondisi ini tentu 
tidak sesuai dengan tujuan penataan fisik kelas itu sendiri yang mempunyai visi membantu menciptakan lingkungan belajar yang menarik dan nyaman bagi siswa.

Peneliti berpendapat bahwa solusi permasalahan tersebut dapat dilakukan melalui perbaikan ruang kelas. Perbaikan ruang kelas ini merupakan langkah nyata untuk menciptakan lingkungan belajar yang nyaman serta meningkatkan kualitas pembelajaran. Hal ini sejalan dengan dengan beberapa studi yang menyatakan penataan kelas dapat mempengaruhi atmosfer pembelajaran (Benson, 2011; Rimm-Kaufman, La Paro, Downer, \& Pianta, 2005; Williamson, 2008). Penataan lingkungan fisik kelas ini meliputi banyak hal, diantaranya penataan tempat duduk, penataan perabotan, penataan ruang gerak (Akbar et al., 2016), pencahayaan, penghawaan atau suhu udara, akustik, keindahan (Karwati, n.d.) serta penambahan musik latar (Syaifurahman, 2013).

Penataan ruang kelas belum banyak dikembangkan di sekolah dasar terutama pada pembelajaran tematik. Beberapa penelitian terdahulu menunjukkan hasil yang positif. Untuk mendukung konsep konstruktivis belajar membaca, siswa perlu diberi kesempatan untuk belajar secara mandiri . Selain itu, lingkungan kelas yang tidak nyaman, dapat menghambat siswa untuk belajar (Byl \& Kloet, 2014; Fisher, 2008). Terlebih lagi, untuk mendukung pembelajaran, desain ruang kelas harus dipertimbangkan dalam rangka mendukung pencapaian tujuan pendidikan (Cheryan et al., 2014). Selain itu, untuk meningkatkan kualitas pembelajaran, prestasi, dan motivasi siswa dibutuhkan fitur-fitur dan simbol di dalam kelas disertai pelatihan dan pengembangan guru. Selanjutnya, kriteria ruang kelas digabungkan dengan tema interior yang disesuaikan dengan tahapan usia anak pada masing-masing kelas yang menjadi dasar dalam merancang interior ruang kelas (Fernanda, Asikin, \& Laksmiwati, 2015). Hubungan dengan penelitian sekarang adalah terdapat variabel penelitian yang sama yaitu interior ruang kelas dan lingkungan fisik kelas sehingga penelitian ini relevan dengan penelitian sekarang.

Berdasarkan uraian di atas, maka peneliti merasa perlu dan tertarik melakukan penelitian pengembangan dengan judul "Pengembangan Model Ruang kelas Berbasis Tematik di Sekolah Dasar." Kekhasan produk model ruang kelas ini adalah berorientasi pada kearifan lokal dan disesuaikan dengan tema yang dipelajari oleh siswa. Penelitian pengembangan ini merupakan sebuah alternatif solusi atas permasalahan yang ada, serta sebagai tindak lanjut dan pelengkap penelitian terdahulu.

\section{METODE}

Model penelitian dan pengembangan yang digunakan dalam mengembangan produk desain ruang kelas berbasis tematik pengembangan model Borg \& Gall. Penelitian pengembangan ini menggunakan model pengembangan Borg \& Gall yang telah dimodifikasi menjadi: (1) pengumpulan informasi, (2) perencanaan, (3) pengembangan produk, (4) validasi ahli, (5) uji coba 
lapangan, (6) produk akhir (Gall, Borg, \& Gall, 1996). Prosedur penelitian dan pengembangan dalam penelitian ini terdiri dari (1) studi pendahuluan, (2) perencanaan, (3) pengembangan produk, (4) validasi ahli, (5) revisi hasil validasi, (6) uji lapangan, (7) penyempurnaan produk akhir, dan (8) produk akhir.

Desain uji coba pada pengembangan ini dilakukan melalui dua tahap, yaitu tahap validasi ahli dan uji coba lapangan. Validasi ahli yang dilakukan oleh dua validator ahli, yaitu ahli teknologi pembelajaran dan ahli bahasa. Setelah dilakukan validasi ahli, kemudian akan dilakukan revisi berdasarkan masukan-masukan validator. Hasil revisi tersebut kemudian diuji coba lapangan pada guru dan siswa SDN Tisnonegaran 1 Kota Probolinggo. Subyek coba pengembangan produk penelitian dan pengembangan ini adalah ahli teknologi pembelajaran, ahli bahasa, guru, dan siswa kelas SDN Tisnonegaran 1 Kota Probolinggo.

Jenis data yang diperoleh dalam penelitian ini berupa data kuantitatif dan kualitatif. Data kuantitatif diperoleh dari hasil skor angket validasi uji materi atau isi dan ahli bahasa, hasil angket guru, dan angket siswa yang kemudian dideskripsikan secara kualitatif. Data kualitatif diperoleh dari uraian saran dan komentar perbaikan validator ahli teknologi pembelajaran atau isi, ahli desain, tanggapan guru dan siswa. Instrumen pengumpul data pada penelitian ini terbagi menjadi dua, pertama instrumen pengumpulan data pada pengumpulan informasi pendahuluan dan pengumpul data pada penelitian pengembangan. Untuk instrumen pengumpul data pendahuluan berupa angket guru dan siswa serta pedoman wawancara guru.

Tabel 1. Tabel Kriteria Kevalidan Ruang Kelas Berbasis Tematik

\begin{tabular}{cll}
\hline No. & \multicolumn{1}{c}{ Kriteria Validitas } & \multicolumn{1}{c}{ Tingkat Efektivitas } \\
\hline 1. & $86 \%-100 \%$ & Sangat Baik (dapat digunakan tanpa revisi) \\
2. & $70 \%-85 \%$ & Cukup Baik (dapat dipergunakan dengan revisi) \\
3. & $60 \%-69 \%$ & Tidak Baik (tidak dapat dipergunakan) \\
4. & $0 \%-59 \%$ & Sangat Tidak Baik \\
\hline Sumber:
\end{tabular}

(Sumber: diadaptasi dari Akbar \& Sriwiyana (2011)

Teknik analisis data yang digunakan daalm penelitian ini ada dua, yaitu analisis data kualitatif dan analisis data kuantitatif. Analisis data kualitatif digunakan untuk mengolah data dari ahli dan pengguna. Sedangkan analisis data kuantitatif dilakukan pada skor angket dan tes. Analisis data ini dimaksudkan untuk mengetahui tingkat ketercapaian berdasarkan kriteria yang telah ditentukan dan disajikan pada Tabel 1. Rumus untuk mengolah data secara keseluruhan item adalah sebagai berikut (Akbar \& Sriwiyana, 2011).

$$
\mathrm{Vm}=\frac{T S e}{T S h} X 100 \% \text { dan } \mathrm{Vp}=\frac{T S e}{T S h} X 100 \%
$$

Keterangan:

$\mathrm{Vm} \quad=$ Validitas Isi/materi 


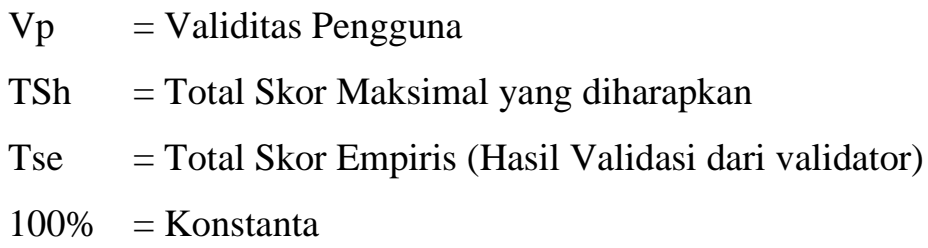

\section{HASIL DAN PEMBAHASAN}

\section{Data Uji Validasi Ahli Teknologi Pembelajaran}

Ahli teknologi pembelajaran yang dipercayakan untuk memvalidasi produk pengembangan yaitu Shofia Hattarina, M.Pd. Beliau merupakan ahli bidang teknologi pembelajaran. Selain itu, beliau juga telah melakukan beberapa penelitian terutama pada sekolah dasar. Hasil perolehan uji validasi produk menunjukkan perolehan sebesar 97,2\%. Adapun hasil validasi disajikan pada Tabel 2.

Tabel 2. Data Uji Validasi Ahli Teknologi Pembelajaran

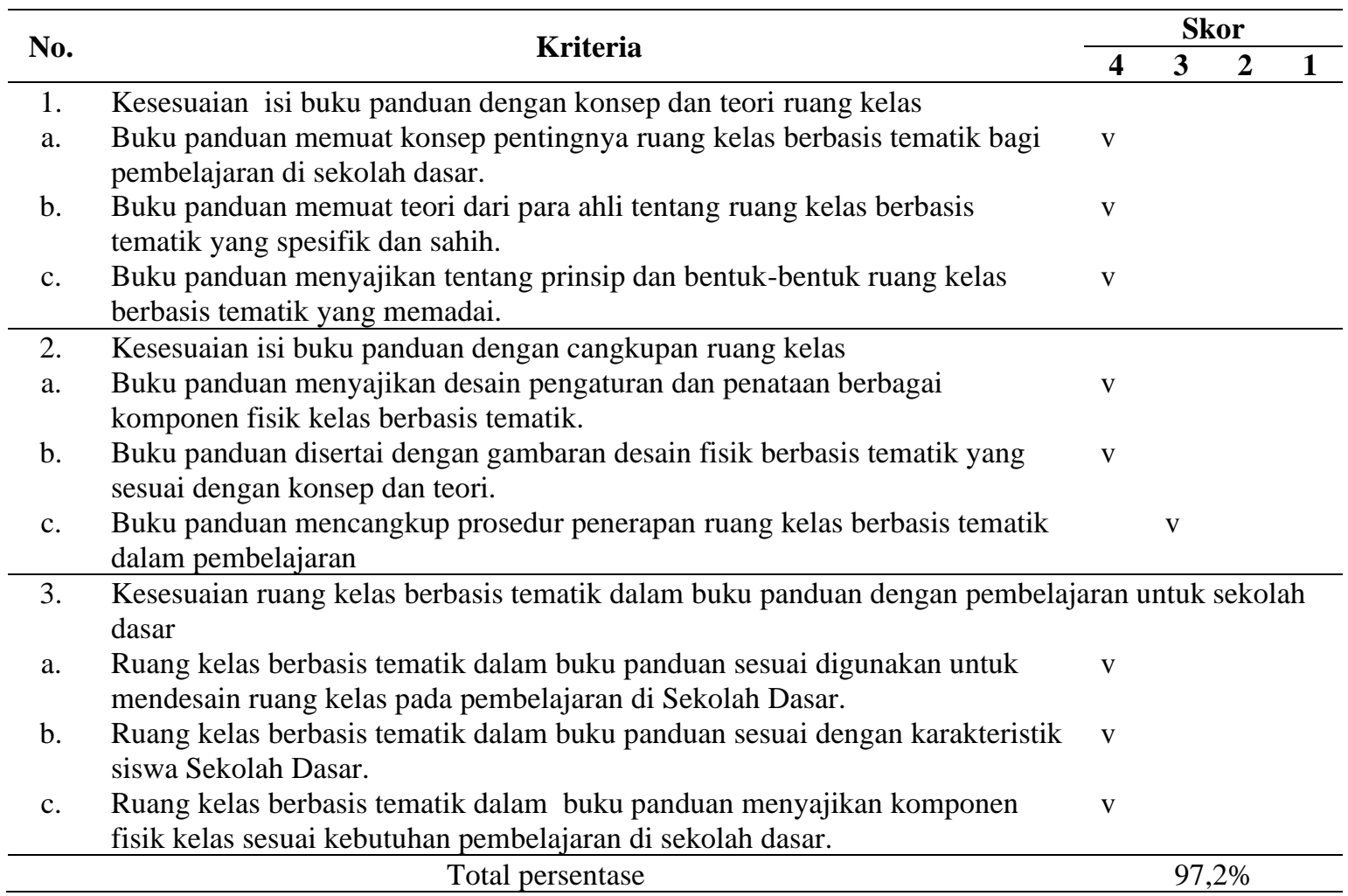

Berdasarkan data dari Tabel 2 diperoleh data bahwa hampir semua aspek dalam kategori sangat baik atau bernilai 4. Hanya satu komponen di bagian kesesuaian isi buku panduan yang mendapat skor 3 yaitu terkait dengan prosedur penerapan ruang kelas dalam buku panduan yang disediakan. Berdasarkan masukan dari ahli teknologi pembelajaran, revisi dilakukan untuk 
penyempurnaan buku panduan yang dikembangkan. Sesuai dengan hasil konversi, maka produk ini dinyatakan valid secara isi atau materi.

\section{Data Uji Validasi Ahli Bahasa}

Validasi bahasa dipercayakan kepada Erfinia Deca Christiasni, M.Pd. yang merupakan ahli bahasa. Beliau berkualifikasi S2 Pendidikan Dasar Konsentrasi Bahasa Indonesia. Hasil perolehan uji validasi perangkat asesmen siswa menunjukkan perolehan hasil sebesar 90,6\%. Adapun hasil validasi ahli bahasa disajikan pada Tabel 3.

Tabel 3. Data Uji Validasi Ahli Bahasa

\begin{tabular}{|c|c|c|c|c|c|}
\hline \multirow{2}{*}{ No. } & \multirow{2}{*}{ Kriteria } & \multicolumn{4}{|c|}{ Skor } \\
\hline & & 4 & 3 & 2 & 1 \\
\hline 1. & Kejelasan pentunjuk penggunaan buku panduan & & & & \\
\hline a. & $\begin{array}{l}\text { Petunjuk penggunaan buku panduan menggunakan bahasa yang mudah } \\
\text { dipahami. }\end{array}$ & $\mathrm{v}$ & & & \\
\hline b. & $\begin{array}{l}\text { Petunjuk penggunaan buku panduan disusun dalam kalimat yang jelas dan } \\
\text { padat. }\end{array}$ & $\mathrm{v}$ & & & \\
\hline c. & Petunjuk disertakan lengkap pada sesuai dengan prosedur penggunaan buku & & & $\mathrm{V}$ & \\
\hline 2. & Kemudahan pemahaman alur materi dalam buku panduan & & & & \\
\hline a. & Buku panduan disajikan dalam bahasa yang komunikatif. & $\mathrm{v}$ & & & \\
\hline b. & Buku panduan disajikan secara runtut dan sistematis. & $\mathrm{v}$ & & & \\
\hline 3. & Ketepatan penggunaan istilah dan EYD & & & & \\
\hline a. & Buku panduan menggunakan kata baku sesuai dengan EYD. & $\mathrm{v}$ & & & \\
\hline b. & Bahasa yang digunakan formal dan santun. & & $\mathrm{v}$ & & \\
\hline c. & Istilah bahasa yang digunakan konsisten dan sesuai dengan isi buku panduan. & $\mathrm{v}$ & & & \\
\hline & Total persentase & & & $6 \%$ & \\
\hline
\end{tabular}

Berdasarkan data dari Tabel 3 diperoleh bahwa komponen kejelasan petunjuk penggunaan buku hanya memperoleh skor 2. Hal ini dikarenakan belum lengkapkanya petunjuk sesuai dengan prosedur penggunaan buku. Saran kedua terkait dengan pemberian skor, masih ditemukan beberapa kata yang belum menggunakan bahasa formal sehingga validator tidak bisa memberi skor maksimum dan hanya berada pada skor 3 saja. Setelah dikonversi pada tabel tingkat kelayakan, produk tersebut termasuk dalam kategori valid.

\section{Data Uji Coba Lapangan}

Subjek dalam uji lapangan ini yaitu guru kelas V SDN Tisnonegaran I Kota Probolinggo. Data uji coba lapangan bertujuan untuk mengetahui tingkat keterterapan produk model ruang kelas berbasis tematik. Tingkat keterterapan diambil dari angket tanggapan guru. Tanggapan guru dikumpulkan melalui angket yang diberikan peneliti pada guru kelas $\mathrm{V}$ sebagai pengguna perangkat asesmen. Hasil tanggapan guru terhadap keterterapan menunjukkan perolehan nilai dengan sebesar 
92,8\%. Setelah dikonversi pada tabel tingkat kelayakan, produk tersebut termasuk dalam kategori keterterapan tinggi. Adapun hasil validasi tahap uji coba lapangan disajikan pada Tabel 4.

Tabel 4. Data Uji Coba Lapangan

\begin{tabular}{|c|c|c|c|c|c|}
\hline \multirow{2}{*}{ No. } & \multirow{2}{*}{ Kriteria } & \multicolumn{4}{|c|}{ Skor } \\
\hline & & 4 & 3 & 2 & 1 \\
\hline 1. & Kemudahan penggunaan buku panduan & & & & \\
\hline a. & $\begin{array}{l}\text { Buku panduan mudah digunakan oleh guru (praktis dari segi ukuran dan } \\
\text { penyajian buku) }\end{array}$ & $\mathrm{v}$ & & & \\
\hline b. & Buku panduan mudah & $\mathrm{v}$ & & & \\
\hline 2. & Kelengkapan dan kejelasan isi buku panduan & & & & \\
\hline a. & $\begin{array}{l}\text { Buku panduan disertai dengan langkah-langkah prosedur melakukan ruang } \\
\text { kelas yang runtut }\end{array}$ & $\mathrm{v}$ & & & \\
\hline b. & Buku panduan disertai contoh ilustrasi desain ruang kelas yang sesui & $\mathrm{v}$ & & & \\
\hline c. & $\begin{array}{l}\text { Setiap langkah dan ilustrasi yang disajikan disertai keterangan yang lengkap } \\
\text { dan jelas. }\end{array}$ & $\mathrm{v}$ & & & \\
\hline 3. & Kemudahan penerapan ruang kelas dalam buku panduan & & & & \\
\hline a. & Prosedur ruang kelas mudah diterapkan untuk kegiatan pembelajaran di SD & & $\mathrm{v}$ & & \\
\hline b. & $\begin{array}{l}\text { Penerapan prosedur ruang kelas didesaian dengan waktu, biaya, pengadaan } \\
\text { sarana dan prasana secara efisien }\end{array}$ & & $\mathrm{v}$ & & \\
\hline & Total persentase & & & & \\
\hline
\end{tabular}

Data model ruang kelas berbasis tematik yang dinyatakan valid diambil dari hasil validasi ahli teknologi pembelajaran dan ahli bahasa untuk merevisi produk agar lebih sempurna. Berdasarkan hasil uji ahli teknologi pembelajaran diperoleh persentase skor sebesar 97,2\%, berdasarkan hasil ahli bahasa diperoleh nilai sebesar 97,2\% dan pencapaian uji coba lapangan sebesar $92,8 \%$. Ketiga hasil tersebut menunjukkan bahwa produk pengembangan model ruang kelas berbasis tematik dalam kategori sangat valid.

Pada kegiatan formasi kelas berbentuk U, siswa tampak fokus dalam mengikuti kegiatan pembelajaran. Hal ini ditunjukkan dalam hasil observasi bahwa ketika guru sedang menjelaskan di papan, siswa yang berada di posisi samping kanan dan samping kiri tampak memutar badan menghadap ke papan tulis. Hal tersebut sebagaimana disajikan pada Gambar 1.

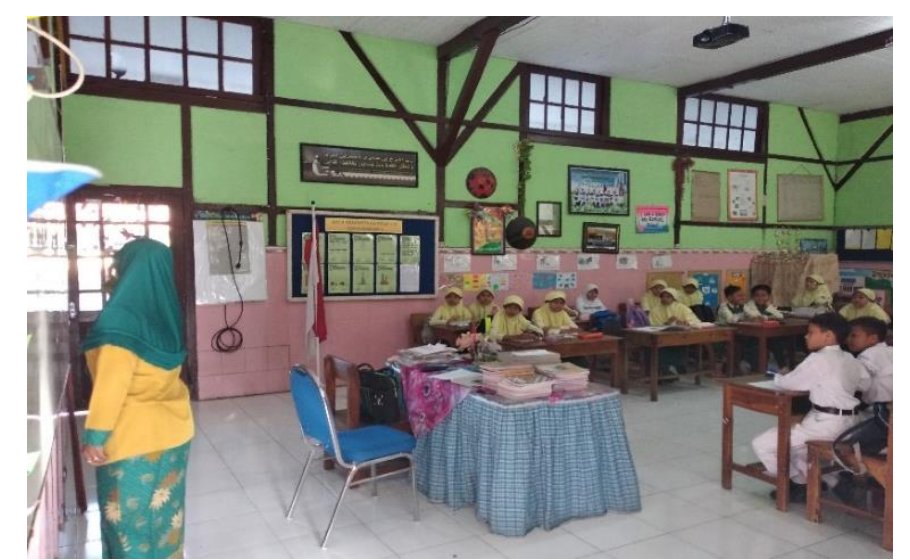

Gambar 1. Pembelajaran Tematik dengan Formasi Bentuk U 
Proses desain ruang kelas meliputi tahapan perencanaan dan pengadaan material kelas secara berkelanjutan, serta melibatkan guru dalam setiap tahapan tersebut. Kegiatan manajemen sarana prasarana dapat dimulai dengan merencanakan dan mengusahakan secara terus menerus benda-benda atau material agar senantiasa siap pakai dalam proses belajar mengajar (Harsanto, 2007; Rofiq, 2009). Selain itu studi menunjukkan bahwa pengelolaan sarana dan prasarana sekolah dapat melibatkan sumber daya manusia seperti guru untuk menunjang berlangsungnya proses belajar dan pengembangan diri siswa (Munawaroh, 2012; Pranandari, Degeng, \& Hanurawan, 2016).

Terkait dengan model lainnya yang dikembangkan, pada Gambar 2 disajikan model formasi pengelompokan terpisah. Pada model ini siswa duduk secara berkelompok dengan jumlah anggota kelompok yang tidak besar dimana arah tempat duduk siswa menyesuaikan kelompok-kelompok tersebut. Berdasarkan hasil pengamatan pada saat pembelajaran berlangsung dengan menggunakan model ini, siswa tampak lebih fokus pada pengerjaan tugas masing-masing, khususnya pada kelompok kecil. Komposisi tempat duduk setidaknya dapat mempengaruhi performansi siswa dalam kelompok kecil karena akan terikat dengan interaksi fisik antar siswa yang terjadi (Ngware, Ciera, Musyoka, \& Oketch, 2013; Pollock, Hamann, \& Wilson, 2011; Stires, 1980).

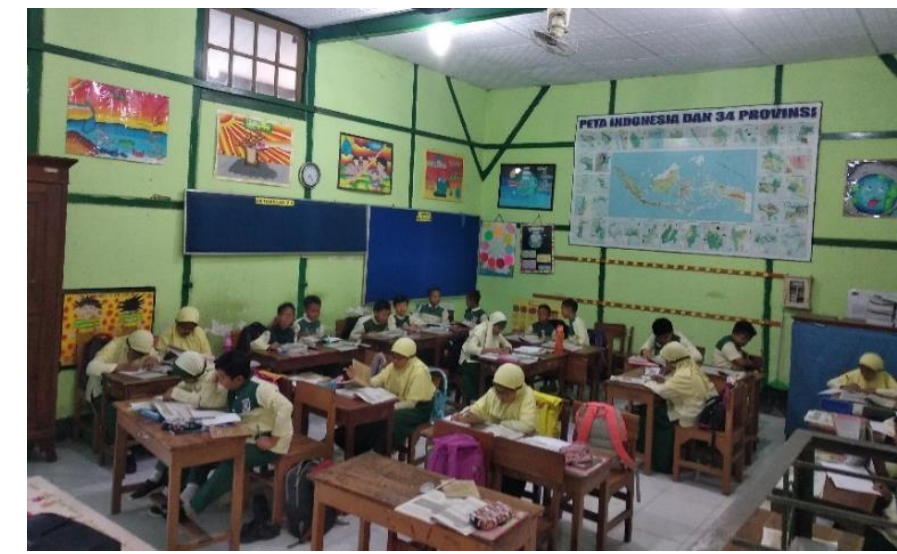

Gambar 2. Pembelajaran Tematik dengan Formasi Formasi Pengelompokan Terpisah

Saran dari ahli bahasa pembelajaran yaitu tujuan pengembangan ruang kelas diharapkan dapat menciptakan kegiatan pembelajaran yang nyaman dan menyenangkan, sehingga akan tercipta pengalaman belajar yang beragam. Hal ini sesuai dengan pandangan Anderson \& Krathwohl yang mengungkapkan bahwa fokus pembelajaran yang bermakna terletak pada pengalaman-pengalaman siswa dalam mengonstruk pengetahuannya, sehingga diharapkan lingkungan belajar dapat memfasilitasi tugas perkembangan tersebut (Krathwohl \& Anderson, 2009).

Aspek keterbacaan dilihat dari hasil uji coba lapangan menyatakan bahwa ruang kelas berbasis tematik ini memiliki keterterapan memperoleh skor 92,8\% dengan kategori sesuai. Saran dari guru adalah agar kegiatan siswa lebih kontekstual. Hal ini sejalan dengan pendapat ahli yang 
menjelaskan desain pembelajaran tematik sebagai produk pembelajaran terpadu yang menggunakan pendekatan tematik dengan melibatkan beberapa mata pelajaran untuk memberikan pengalaman bermakna kepada siswa dengan lingkungan kontekstual (Majid, 2014; Prastowo, 2013).

\section{SIMPULAN DAN SARAN}

\section{Simpulan}

Berdasarkan hasil angket validasi ahli dan angket keterterapan terhadap produk ruang kelas berbasis tematik, maka dapat disimpulkan sebagai berikut. Pertama, yaitu bila ditinjau dari hasil validasi yang diperoleh dapat dikatakan bahwa pengembangan ruang kelas berbasis tematik telah sesuai dengan landasan teoritik maupun penelitian terdahulu. Kedua, bila ditinjau dari hasil keterterapan yang diperoleh dapat dikatakan bahwa pengembangan ruang kelas berbasis tematik telah dapat diterapkan pada kelas V sekolah dasar.

\section{Saran}

Berdasarkan masukan-masukan ketika proses penelitian, maka penelitian ruang kelas berbasis tematik mempunyai beberapa saran pengembangan. Pertama, yaitu terkait saran pemanfaatan dari hasil kajian produk yang telah diimplementasikan maka guru hendaknya memahami maksud dari produk ruang kelas berbasis tematik dengan membaca terlebih dahulu buku panduan secara utuh. Kedua, saran bagi para peneliti berikutnya hendaknya mengembangkan ruang kelas berbasis tematik dalam setiap jenjang pendidikan yang relevan dan strata pendidikan yang lain (kelas yang berbeda), agar dapat diperoleh informasi mengenai tingkat kepraktisan maupun keterterapannya. Ketiga, saran diseminasi ke sekolah yang lain dengan pertimbangan menganalisis kebutuhan dan karakteristik sekolah yang ada.

\section{DAFTAR RUJUKAN}

Akbar, S., A'yun, I. Q., Satriyani, F., Widodo, W., Paranimmita, R., \& Ferisa, D. (2016). Implementasi Pembelajaran Tematik di Sekolah Dasar. Bandung: Remaja Rosdakarya.

Akbar, S., \& Sriwiyana, H. (2011). Pengembangan kurikulum dan pembelajaran ilmu pengetahuan sosial. Malang: Cipta Media.

Benson, P. (2011). Language learning and teaching beyond the classroom: An introduction to the field. In Beyond the language classroom (pp. 7-16). Springer.

Byl, J., \& Kloet, B. V. (2014). The Effect of The Physical Classroom Environment on Literacy Outcome. America: United States of America.

Cheryan, S., Ziegler, S. A., Plaut, V. C., \& Meltzoff, A. N. (2014). Designing classrooms to maximize student achievement. Policy Insights from the Behavioral and Brain Sciences, 1(1), 4-12.

Fernanda, G., Asikin, D., \& Laksmiwati, T. (2015). Interior Ruang Kelas Sekolah Dasar dengan Pendekatan Konsep Permainan Tradisional pada Program Full day School di Malang. Jurnal Mahasiswa Jurusan Arsitektur, 3(1).

Fisher, E. S. (2008). The effect of the physical classroom environment on literacy outcomes: How 3rd grade teachers use the physical classroom to implement a balanced literacy curriculum ( $\mathrm{PhD}$ Thesis). University of Missouri-Columbia.

Gall, M. D., Borg, W. R., \& Gall, J. P. (1996). Educational research: An introduction. Longman Publishing. 
Harsanto, R. (2007). Pengelolaan kelas yang dinamis. Yogyakarta: Kanisius.

Kartika, N. K. R., Natajaya, I. N., \& Rihendra, K. (2013). Determinasi Lingkungan Sekolah, Disiplin Belajar, dan Kualitas Pembelajaran Terhadap Prestasi Belajar Siswa Pada Mata Pelajaran Ekonomi. Jurnal Administrasi Pendidikan Indonesia, 4(1).

Karwati, E. (n.d.). Priansa, 2014. Manajemen Kelas Classroom Management Guru Profesional Yang Inspiratif, Kreatif, Menyenangkan Dan Berprestasi. Bandung: Alfabeta.

Krathwohl, D. R., \& Anderson, L. W. (2009). A taxonomy for learning, teaching, and assessing: A revision of Bloom's taxonomy of educational objectives. Longman.

Majid, A. (2014). Pembelajaran tematik terpadu. Bandung: PT Remaja Rosdakarya.

Maryana, R., \& Rachmawati, Y. (2013). Pengelolaan lingkungan belajar. Prenada Media.

Munawaroh, I. (2012). Esensi “Menghidupkan” Ruang Kelas Bagi Penyelenggaraan Pembelajaran Efektif. Majalah Ilmiah Pembelajaran.

Ngware, M. W., Ciera, J., Musyoka, P. K., \& Oketch, M. (2013). The influence of classroom seating position on student learning gains in primary schools in Kenya. Creative Education, 4(11), 705.

Pollock, P. H., Hamann, K., \& Wilson, B. M. (2011). Learning through discussions: Comparing the benefits of small-group and large-class settings. Journal of Political Science Education, 7(1), 48-64.

Pranandari, I. W., Degeng, I. N. S., \& Hanurawan, F. (2016). Korelasi Antara Persepsi Siswa Tentang Pengelolaan Kelas, Hubungan Teman Sebaya (Peer Relationships), dan Hasil Belajar Siswa Kelas IV SD Negeri Kecamatan Sananwetan Kota Blitar. Jurnal Pendidikan: Teori, Penelitian, Dan Pengembangan, 1(3), 480-485.

Prastowo, A. (2013). Pengembangan bahan ajar tematik. Yogyakarta: Diva Press.

Rands, M. L., \& Gansemer-Topf, A. M. (2017). The room itself is active: How classroom design impacts student engagement. Journal of Learning Spaces, 6(1), 26.

Rimm-Kaufman, S. E., La Paro, K. M., Downer, J. T., \& Pianta, R. C. (2005). The contribution of classroom setting and quality of instruction to children's behavior in kindergarten classrooms. The Elementary School Journal, 105(4), 377-394.

Rofiq, A. (2009). Pengelolaan kelas. Malang: Direktorat Jendral PMPTK.

Stires, L. (1980). Classroom seating location, student grades, and attitudes: Environment or self-selection? Environment and Behavior, 12(2), 241-254.

Syaifurahman, T. U. (2013). Manajemen dalam pembelajaran. Jakarta: PT Indeks.

Weinstein, C. S. (1981). Classroom design as an external condition for learning. Educational Technology, $21(8), 12-19$.

Wetherill, E. A. (2002). Classroom design for good hearing. Better Schools for a New Century, American Institute of Architects San Francisco, April 1999.

Williamson, J. (2008). Literacy in the Student-centered Classroom: A Practical Approach to Setup, Design, and Implementation. R\&L Education. 